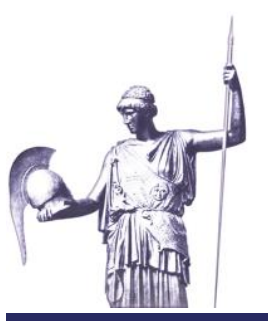

Connections: The Quarterly Journal

ISSN 1812-1098, e-ISSN 1812-2973

Editorial

Philipp Fluri, Connections QJ 18, no. 3-4 (2019): 5-6

https://doi.org/10.11610/Connections.18.3-4.00

\title{
South Caucasus, PME and Intelligence Services' Transformation in Focus
}

\section{Philipp Fluri}

Geneva Centre for Security Policy, https://www.gcsp.ch

This present issue of Connections. The Quarterly Journal looks into a number of issues: professional military education and its role in deepening defense capabilities with a special focus on the South Caucasus, the defense cooperation of the South Caucasus nations with both Russia and NATO which, according to some commentators, may result in a new form of a 'Great Game' rivalry between the cooperation partners, the specific 'military school culture' of the Dr. Franjo Tudjman Defense Academy of Croatia, and the transformation experiences and lessons (to be) drawn from them in the intelligence and state-security services and communities of the Czech and the Slovak Republics and Latvia. The latter three are a first installment of a larger collection of articles dedicated to intelligence and state security services transformation after the end of the Cold War.

None of the important time-critical processes described and analyzed in the articles presented here could have been realized without expert advice provided by NATO initiatives and the cooperation with NATO member and partner countries. Thus, the Defense Education Enhancement Program (DEEP) played and continues to play a crucial role in Professional Military Education (PME) and interoperability in the Southern Caucasus.

Democratic values and professionalism, transparency, and respect for the citizen, human rights, and civic freedoms also played a decisive role in the reorientation and transformation of the state security and intelligence services after the Cold War. Czech, Slovak, and Latvian colleagues have provided fascinating insights in hitherto under-documented transition and transformation experiences in their home countries and the role models of transparency and professionalism played. Once the Berlin Wall had fallen and the Soviet regime collapsed, democratization processes were initiated in all areas of social and political life, which also demanded the transformation of the state security services, based on new and adapted legislation, and a functioning parliamentary 
and executive oversight and transparency system which still needed to be installed and instructed.

Whereas the transformation process in the Czech and Slovak Republics went mostly peacefully and in an evolutionary manner in spite of the reversal of 'culture' they implied, events in Latvia which had lost its statehood de facto (if not de iure) in the years of Soviet occupation can hardly be described in the language of 'transformation.' The politicized security services in Latvia had worked for an occupational force, ensuring unconditional submission of the population to the regime. They needed to be demolished and rebuilt to function properly in the service of a democratic society.

Future issues of Connections will provide more insights into the transition and transformation experience of state security and intelligence services in new democracies.

\section{Disclaimer}

The views expressed are solely those of the author and do not represent official views of the PfP Consortium of Defense Academies and Security Studies Institutes, participating organizations, or the Consortium's editors.

\section{Acknowledgment}

Connections: The Quarterly Journal, Vol. 18, 2019 is supported by the United States government. 